of fever. Noreover, in many cases it is necessary to find out what experiences in the past or present life of the patient produce emotions. For tinis purpose the paticnt sits at case, with hands on the electrodes. Varjous words are spoken, or topics of conversation are brought up; the galvanometer shows when a sensitive subject has beren touched.

87 Malison Treme.

\section{PLAGUE AMONG RATS IN SAN FRANCISCO.}

WILLIAM B. WHERRY, M.D., AGXES WALKER, M.D., ANi EDGAR H. HOWELL, M.D.

Bacteriologists to the I'lague Laboratory of the San Francisco Board of IIealth.

SAN FRANCISCO.

The following notes on epizootic plague in rats are published in the belief that they may prove of interest to other workers.

It will be observed that the relative merits of the microscopic and naked-eye methods of detecting plague in rats have been thoroughly tested. Our data are drawn from the microscopic and anatomic appearances of 14,184 rodents examined between Sept. 13, 190\%, and Jan. 14, 1908. We agree with the last Indian Commission $^{1}$ in their belief that the naked-eye method alone furnishes enough data to pass on a rat as being plague infected or not. Like them, however, we preferred to combine the two methods first in order to rule ou any fallacies which might be introduced by unknown local conditions. So far no disease of rats has been encountered which could possibly cause confusion, with the exception of a few instances which will be cited below under "Diseases in Rats Resembling Plague."

\section{METILODS OF EXAMINATION EMPLOYED.}

The rats were brought daily from the various district headquarters and entered serially in a book, where notes were recorded concerning the address of the rat, its species, etc. After being tacked out on a shingle, each rat was completely dissected by Mr. A. Venzke, who gained a great experience in similar work under Dr. Curric, Public Health and Marine-Hospital Service, during the previous epidemic in San Francisco.

A smear from the spleen of each rat was examined microscopically, and whenever the anatomic conditions indicated, from the glands, liver, heart's blood, etc. ${ }^{2}$

Whenever suspicious bipolar staining bacilli were found their pathogenicity. was tested by rubbing a bit of the tissue to be tested into a lightly scarified area (about an inch square) on the abdomen of a guinea-pig, rabbit or white rat. 'These animals have been named in the order in which they have proved most satisfactory. In addition, if the condition of the rat warranted, cultures from the spleen and heart's blood were made on +1 agar slants. On the death of the experimentl animal, note was always made of a typical local reaction at the point of vaccination. However, this proved un-

1. Jour. Hyg., 1907, vii, 324

2. In our routine staining, we have found Wright's, Jenner's and the carbol-thionin stains very satisfactory, but prefer the following thionin-methylene blue combination, derised by R. A. Archibald, D.V.S. It stains almost instantaneously, either after or without fixation by healt.

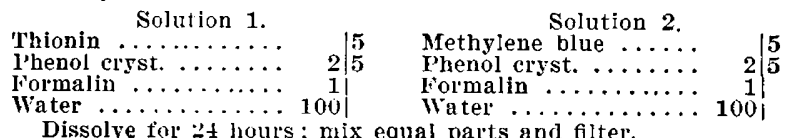

necessary, for we lave had no mortality from plague among our stock guinea-pigs, nor have we found fleas on them. The experimental animals have been kept throughout in screened jars. .

Cultures obtained from the spleen and heart's blood of the rats, and from the experimental animals, were then further tested for the production of typical involution forms on salt agar. We have grown the cultures to be so tested for twenty-four or forty-eight hours at $3 \%$ rlegrees $C$. on +1 agar, containing 2 to 3.5 per cent. forlium chlorid. ${ }^{3}$

In a number of instances the cultures so tested have been retested for pathogenicity. We have not been able to test for the production of stellactites in oiled bouillon owing to the vibration of our laboratory building.

\section{OBSERVATIONS IN DETAIL.}

Bearing in mind the statement made by Hetch and Otto ${ }^{4}$ that in rats experimentally infected through the oral and intestinal mucosa, plague bacilli could be found in greater numbers in the liver than in the splcen, we examined smears from both these organs in a series of 1,200 rats. The results did not justify the additional labor. Anatomic conditions which would possibly. indicate the natural occurrence of intestinal infection in rats have been encountered in only one instance:

No. 2816. M. decumanus; sick when caught; glands not enlarged; spleen enlarged and congested; right lung whitish, and contains calcareous particles; liver shows many pinpoint yellowish foci of necrosis. Typical bipolar staining bacilli were very much more numerous in the liver than in the spleen. A guinea-pig was inoculated subcutaneously with an emulsion of the liver on Oct. 16, 1907. Died on Oct. 18, 1907, with typical anatomic reaction at the point of inoculation, glands and spleen. Cultures from the guinea-pig proved to be $B$. pestis.

Table 1 will indicate the number and kinds of rodents examined between Sept. 13, 190\%, and Jan. 14, 1908, and the per cent. found infected.

\begin{tabular}{|c|c|c|c|c|}
\hline \multicolumn{5}{|c|}{ TABLE 1.} \\
\hline Species. ${ }^{5}$ & $\begin{array}{l}\text { Total No. } \\
\text { Examined. }\end{array}$ & $\begin{array}{l}\text { Species, } \\
\text { Per Cent. }\end{array}$ & $\begin{array}{c}\text { Total } \\
\text { Infected. }\end{array}$ & $\begin{array}{l}\text { Infected, } \\
\text { Per Cent. }\end{array}$ \\
\hline Mus aceumanus. & 13,982 & 98.79 & 139 & 0.99 \\
\hline M. rattus . . $\ldots \ldots \ldots$ & $10 \overline{5}$ & 0.73 & 1 & 0.95 \\
\hline $\begin{array}{l}\text { I. } r \text { alcxandrinus...... } \\
\text { M. musculus........... }\end{array}$ & $\begin{array}{l}51 \\
16\end{array}$ & 11.35 & 2 & 3.84 \\
\hline Totals & 14,184 & & 142 & \\
\hline
\end{tabular}

It is evident that the most common rat in San Francisco is $M$. decumanus, and that the greater number found infected are of this species.

3. We have noted that plague cultures will not give typical in volution forms in twenty-four hours on 2 per cent. sodium chlorid agar under certain conditions. This is when the salts which precipitate out of bouillon on its cooling are filtered out before the addition of the agar. However, the presence of 3 per cent. sodium chlorid obviates this difficulty.

4. Klin. Jahrb., 1903, ii, No. 3.

5. The following characters, somewhat roughly stated, will serve for the routine differentiation of these three species:

M. decumanus: The Norway rat. Often reaches a great size, tail about the same length or shorter than body, heavily built, coat of coalse gray hair, ears smaller in proportion to size than in the next two species.

$M$. rattus: of more slender and delicate proportions than $M$. decumanus, tail about an inch longer than body, coat of fine grayish brown or brownish black hair.

11. rattus alexandrinus: The Egyptian roof rat or white bellied rat, resembles $M$. rattus in general appearance except that the hairy coat on the whole under surface of the body is pure white with sharply demarcated borders.

The Norway rat, according to D. S. Jordan (Manual of the Ver tebrates of North America), was introduced into America about 1775, whence it has practically expelled $M$. rattus. The latter species is the ship lat, par excellence, though the other two species also occur on ships. Most of the $M$. rattus brought to us have come from ships or wharves, though a few have been caught a mile from the docks. A few young of the variety, $M$. $r$. alexandrinus have been caught a mile or so inland, showing that this variety probably breeds on shore to a small extent. 
Complete postmortem notes on 88 "positiva" rats show that $i t$ of these had enlarged and congested glands; 13 of the 74 showed a typical primary bubo (6 inguinal, 1 sulmmaxillary, 1 axillary). Only 28 presented the characteristic anatomic picture of general subcutaneous congestion, enlarged and congested glands, splenic tumor and hydro- or hemo-thorax. The inguinal glands, either alone or along with other glands, were enlarged and congested in $4 \%$, the axillary glands in 30 , and the submaxillary glands in 33 instances. No single characteristic ahnormality invariably occurred in the rats of this series, as shown by Table 2 .

\section{TABLE 2.}

Subcutaneous injection.

Enlarged congested glands.
Enlarged congested spleen

Fnlarged congested spleen

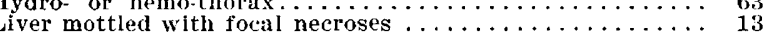

Most of the 88 rats were fresh; only 7 showed much postmortem decomposition, and in these typical bacilli were fairly numerous, either in the spleen or in a gland.

While the aid of a microscope can not always be dispensed with in determining whether a rat is infected with plague or not, the following instances will emphasize the relatively greater value of naked-eye postmortem appearances:

No. 11,597. M. decumamus. Marked subcutaneous injection, all regional glinds enlarged, spleen twice normal size, fluid in thorax, surface of liver roughened. Smears from spleen showed very few clumps of solid staining rods, not resembling $B$. pestis morphologically. Smears from the glands showcd no bacteria. Cultures from the spleen gave a pure growth of $B$. pestis.

No. 11,267. M. decumanus. Subcutaneous injection, submaxillary and right and left inguinal glands enlarged and congested, enlarged dark spleen, liver mottled with foci of necrosis. Some bacilli which did not present a typical bipolar stain were found in spleen smears. A guinea-pig vaccinated with spleen tissue died of typical plague in four days. Cultures from the guinea-pig showed the presence of postmortem in vaders besides the fine colonies of $B$. pestis. The latter produced typical involution forms on salt agar.

VIRULENCE OF BACILLUS OF XATURAL RAT PLAGUE IN SAN FRANCISCO.

From Table 3 it will be seen that the bacillus of natural rat plague in San Francisco is quite as virulent as the strains tested in Bombay. ${ }^{6}$

\section{TABLE 3.} Animals used, method of
inoculation.

Time precedins death in days.

A verage time preceding

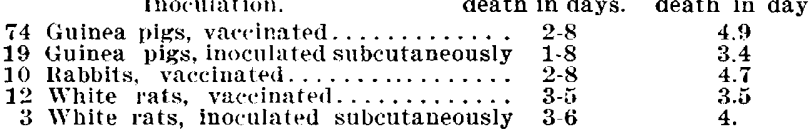

\section{CIIRONIC PLAGUE IN RATS.}

It may be well to emphasize here the occurrence of certain involution forms of the $B$. pestis in the tissues of human beings and rats. These are the socalled yeast-form or, better, as styled by the last Indian Commission, "coccoid" form of the bacillus. We have examined the buboes of several humans where the organism appeared as thousands of pale circular discs, of slightly greater diameter than that presented by the bipolar-staining rod form. We have encountered these "coccoid" forms in the splenic abscess of one case of chronic plague, and in one case of acute plague in rats, as follows:

No. 10.019. M. decumanus. Cervical bubo, liver mottled, spleen concrested and on section a small abscess was found at

\footnotetext{
6. Jour. IIyg., 1907 , vil, 358.
}

one end. Smears from splenic abscess showed numerous typ: ical bipolar staining rods along with numerous "coceoid" forms. A few groups of typical rods were seen in smears from the liver, none in the gland smears. A guinea-pig, vaccinated with the contents of the splenic abscess on Dec. 16,1907 , died on Dec. $20,190 \bar{\gamma}$, with the typical anatomic findings of plague. Cultures from the guinea-pig gave typical involution forms on salt agar.

No. 18,780, M. decumanus. Marked subeutaneous injection, left inguinal and axillary glands much enlarged and deeply congested, fluid in thorax, spleen very red but not much enlarged. Smear, "spleen," full of "coccoid" forms; smear, "gland," shows enormous numbers of bipolars and "corcoill" forms. Guine: pig vaccinated $2 / 11$, dead $2 / 14$, typical anatomically. Rat cultures look like plague. Involution forms on salt agar.

\section{DISELISIS IN RLTS RESEALBLING PLAGUE.}

As already stated, we have encountered a fow rats. which were suspicions anatomically and microscopically, from which the $B$. grestis was not jsolated. In eertain instances a typical reaction was produced in guineapigs by vaccination or inoculation, but the organisms isolated failed to give the biochemical tests for $B$. pestis. We have not had time to work over this material carefully and (an not state vet whether the fault was technical or whether some other organism was responsible for these failures. However, we can cite one instance of a rat which presented an anatomic and microscopic picture which might have been confusing had not the animal and bacteriologic tests been male. The notes on this rat are as follows:

No. 15,670. M. decumanus. Subcutaneous congestion well marked all over abdomen and neck, submaxillary glands enlarged and congested, liver dark and swollen, spleen large and dark red, lungs congested in areas, left lung adherent to thoracic wall, no fluid in thorax, pericardium thickened and congested, and, in it, just to the right of apex of heart, is a tumor-like swelling about $3 / 4 \times^{1 / 2} \times 1 / 4$ of an inch, filled with a greenish yellow caseous pus. Microscopically the pus contained thin, curved and straight rods, with metachromatic granules, resembling the granular forms of the diphtheria bacillus. The submaxillary gland contained numerous rods about the size of the typhoid bacillus, varying somewhat in length and often presenting a typical bipolar staining.

A white rat vaceinated, with the submaxillary gland was chloroformed and found perfectly normal six days later. Pure cultures of a non-motile member of the colon gronp were obtained from the submaxillary gland, $i$. e., the bacillus coagulated milk, produced indol and fermented dextrose, levulose, lactose, galactose, saccharose, maltose and manite with gras production, but produced neither ach nor gas from inulin. It grew luxuriantly on 3.5 per cent. salt agar, and produced no involution forms. An agar slant of subcultures injected intraperitoneally into white or wild rats ( 1 . decumanus) produced a hemorrhagic peritonitis with septicemia. In smears from these experimentally infected animals the morphologic resemblance to $B$, pestis was striking. The abscess in the pericardium was due to an organism probably identical with $M$ yeobacterium pseudotuberculosis (Kutscher). A considerable number of chronic subcutaneous and visceral abscesses in rats, due to this organism, have been encountered.

\section{SUMMARY.}

While we have not given the details concerning all of the rats we have tested by bacteriologic and animal inoculation experiments, we have to agree with the last Indian Commission that, with experience, the chances of missing a plague-infected rat by the naked-eve method of examination alone are extremely small. Recently we have abandoned the wholesale preliminary

T. Chester, F. D.: Manual of Determinative Bacteriology, 1:001. p. 355 . 
microscopic examinations and substituted the anatomic dissections followed by the bacteriologic and animal tests of anatomically suspicious rats.

Of 14,184 rodents examined, 98.97 per cent. were $M$. decumanus; 0.73 per cent. $M$. rattus; 0.35 per cent. $M$. rattus alexandrinus, and 0.11 per cent. $M$. musculus. By far the greater number found infected were $M$. decumanus.

A brief summary of the anatomic and microscopic characters of acute and chronic plague in rats is given with the citation of specific instances.

The results of animal inoculation experiments show that the bacillus of natural rat plague in San Francisco is quite as virulent as the strains tested in Bombay by the last Indian Commission.

\section{OCULAR ROTATIONS IN PARESIS.*}

FRANCIS VALK, M.D.

Professor of Iiseases of the Eye, Post-Graduate Medical School and Hospital.

NEW YORK CITY.

At the last meeting of this Section our honored chairman, speaking of the ocular muscles, stated: "One who has spent much time in investigation and has written largely in expression of his views recently said at the close of a most interesting address, 'I feel as if I were only on the threshold of this study'," and also quoted another ophthalmologist as saying: "Ophthalmology is finished, you will find nothing new in it.". These quotations are certainly reasonable cause for further thought on the ocular rotations, and perhaps the last word has not been said on this interesting subject. Carl Weiland may well ask: "Are our present ideas about the mechanism of the eye movements correct?" Furthermore, since the discussion of the paper, "Some Axioms Concerning Ocular Rotations," by our present chairman, Dr. G. C. Savage, ${ }^{1}$ I have felt much interested in the subject of the rotations of the eye as it moves about in the field of version; the action of the ocular muscles in causing these rotations, their points of action and the phenomena presented by their pathologic condition-paresis. A careful study of the various writings on this subject has not rendered the matter at all clear to me, even though our chairman has stated that his conclusions are axioms.

To present one's individual opinions on this subject in a clear and concise manner is difficult, and to demonstrate any theory is more so, especially when we find so many diversified writings on the ocular rotations and the diagnosis of paresis. I may state that this paper will refer to eyes that have normal rotation about the center. It will deal with the subjects of increased or diminished rotation as found in that anatomic condition causing heterophoria and that pathologic condition causing paresis, with the phenomena pertaining thereto.

I wish to lay special stress on the term paresis in this paper. In complete paralysis of an eye muscle it does not seem to me that there can be any question as to the diagnosis, but in paresis the subject, according to the schemes of the writers of all our text-books, seems to be extremely complicated. I understand that neuralogists make a clear distinction between these two terms, and, according to my views, the distinction between paralysis

\footnotetext{
* Read in the Section on Ophthalmology of the Amprican Medi cal Association at the Fifty-eighth Annual Session, held at Atlantle City. June, 1907.

1. 'The Jolrial A. II. A., Aug. 4, 1006.
}

and paresis of the ocular muscles should be clear and well i'cefined.

In paralysis we have "the suspension or abolition of a functional power, especially in the nervous system, in which case there is a temporary or permanent loss of power of motion," etc. (Fostcr), while in paresis we have "an incomplete paralysis, especially when not associated with any demonstrable organic change" (Foster). Furthermore, I do not think that paresis should be classed under the conditions of heterophoria. I would consider heterophoria as an inability of the oscular muscles to perform a certain function. It is due to certain conditions, anatomic rather than pathologic, in which the muscle fails to act to its normal extent in the field of version. Hence I would call attention to the last two terms, as they apply with particular force in a study of the rotations of the eyes.

In paralysis the function of an ocular muscle is completely lost and the visual line must rotate or deviate in the direction of the muscles antagronistic and remain in that position. An exception to this is found in ophthalmoplegia externa, in which motion is completely Jost in all directions and the eye remains fixed. In paresis the function of the ocular muscle is but partly destroyed and the visual line fails to turn in the direction of the paretic muscle beyond the median line of the orbit with a consequent diplopia. In heterophoria, with normal acuity of vision, we do not have diplopia when the look is in infinity. I state this again for the reason that it has been said that a diagnosis of paresis is made when the eyes are directed to the upper part of the field of version, with the visual line directed strongly to the right or left. It is also stated that in one of these positions the superior rectus acts as an elevator of only one eye, while the inferior oblique of the fellow eye raises the visual line (Duane, in Posey and Spiller). I can not agree with this proposition, as paresis of the inferior oblique, if it does occur, must cause diplopia with decided tipping of the image toward the side of the paretic muscle.

The most essential point to establish is the position of the eyes when at rest, with the look in infinity, in which the ocular muscles are in a state of normal tonicity. This position of the eyes is now well defined by all ophthalmologists as the first or primary position and one from which the eyes may be moved by the normal function of the ocular muscles to any secondary position in the field of version. Now, in this study of the ocular rotations and the primary position it must be understood that the position of infinity is not at twenty feet, but is any point in space, as a star. I wish to make this distinction, as practically we do have a certain amount of convergence at twenty feet, the usual distance for testing the vision. Furthermore, another essential is the visual acuity which must be at its best. In other words, in testing the eyes for the ocular rotations the visual acuity must not be reduced by any artificial means. Visual acuity reduced by mechanical means may be permissible at times, but it is not essential.

Bearing these two points in mind, we are now prepared to consider the rotations of the eyes, not from the standpoint of the rotations of a rubber ball ur other artificial apparatus, but simply from an anatomic and a clinical point of vicw.

It seems to me like "carrying coals to Newcastle" to come before this association of ophthalmologists and speak of the anatomy of the orbits, but I wish to make some suggestions for your consideration in reference to 